\title{
Effect of Organizational Leadership and Training on Teachers' Performance: The Case of Degga Woreda Public Primary Schools
}

\author{
Feyissa Mitiku \\ Bonga University, Department of Public Management \\ Biniam Getnet \\ Bonga University, Department of Management
}

\begin{abstract}
The aim of this study was to investigate factors influencing teachers' motivation and their effect on performances: in the case of Degga Woreda public primary schools. Descriptive and explanatory research designs were adopted with both qualitative and quantitative research approach. The study population comprised a totaling 297 teachers from primary schools and 170 teachers were sampled for this study by using Yemane (1967). Also to identify the target respondents from total population of the study systematic random sampling techniques was used. Questionnaires, interview, and researcher observation were served as data collection instruments. The data were analyzed using descriptive (mean and standard deviation) and inferential statistics (multiple correlations and regression). The analysis was supported by the statistical software such as Statistical Package for Social Scientists 20 versions and Analysis of Moment Structures 22 versions. The key findings of doing so; organizational leadership and training and development have a positive direct effect on the performance of teachers. The study concluded that organizational leadership and training have a major positive direct effect on the performance of teachers. Finally, the study recommended that the regional education bureau, woreda education office, and head of schools will have developed a national training policy and award programs based on performance.
\end{abstract}

Keywords: Organizational Leadership, Training, Performance of Teachers

DOI: $10.7176 /$ RHSS/10-3-01

Publication date: February $29^{\text {th }} 2020$

\section{Introduction}

The use of formal training program is related with significantly higher productivity growth. Organization with excessive training opportunities should experience lower turnover rates. However, an interesting finding included a positive relationship between training and the discharge rate.

The main of teacher training is to develop educational skills that are compatible with education policies and to enable teachers to deliver these policies. There exists a relationship between teacher productivity and teacher training, including formal pre-service University education, in service professional development and informal training acquired through one the job experience. According to Clotfelter (2006), better trained and more experienced teachers tend to be assigned to students of greater ability and fewer discipline problems.

According to Michael (2002), organizational leadership is a dual focused management approach that works towards what is the best for individual and what is best for group as a whole simultaneously. It is an attitude and work ethic that empowers and recognize an individual in any role to lead from the top, middle or bottom of an organization. Also organizational leadership is considered as a key to success of firms. Leadership is about getting things done the right way to do that you need people to follow you need to have them trust you. Moreover, if you need them to trust you and do things for you and the organization, they need to be motivated (Baldoni, 2005). Good leadership relation is an important factor in fostering employee motivation. Providing employees with the supports they needed such as helping them with job related problems, good communication, recognition, responsibility, empowerment, fairness of treatment, trust and regular feedback about employee performance increases employee motivational level. Motivation is purely and simply a leadership behavior. It stems from wanting to do what is right for people as well as for the organization. Leadership and motivation are active processes in management (Rukhmani, 2010).

Performance of the teacher is considered as what a teacher does and what he doesn't do. The worker could be only satisfied when they feel themselves competent to perform their tasks, which is attained through better training programs. Factors of teacher motivation have impacts on teacher performance as follows. Teacher performance involves quality and quantity output, presence at work, accommodative and helpful nature and timeliness of output. Also teacher performance is higher in happy and satisfied teachers and the management find it easy to inspire high performers to achieved organization goals (Kinicki, 2007). The followings are some of teacher's performance. Obviously, there are many problems concerning with teachers' performance in Ethiopia, but there has been limited research on the teachers' performance. 


\section{Description of the Study Area}

Descriptive of the study area was described as follows.

Figure 2. 1 Location Map of the Study Area

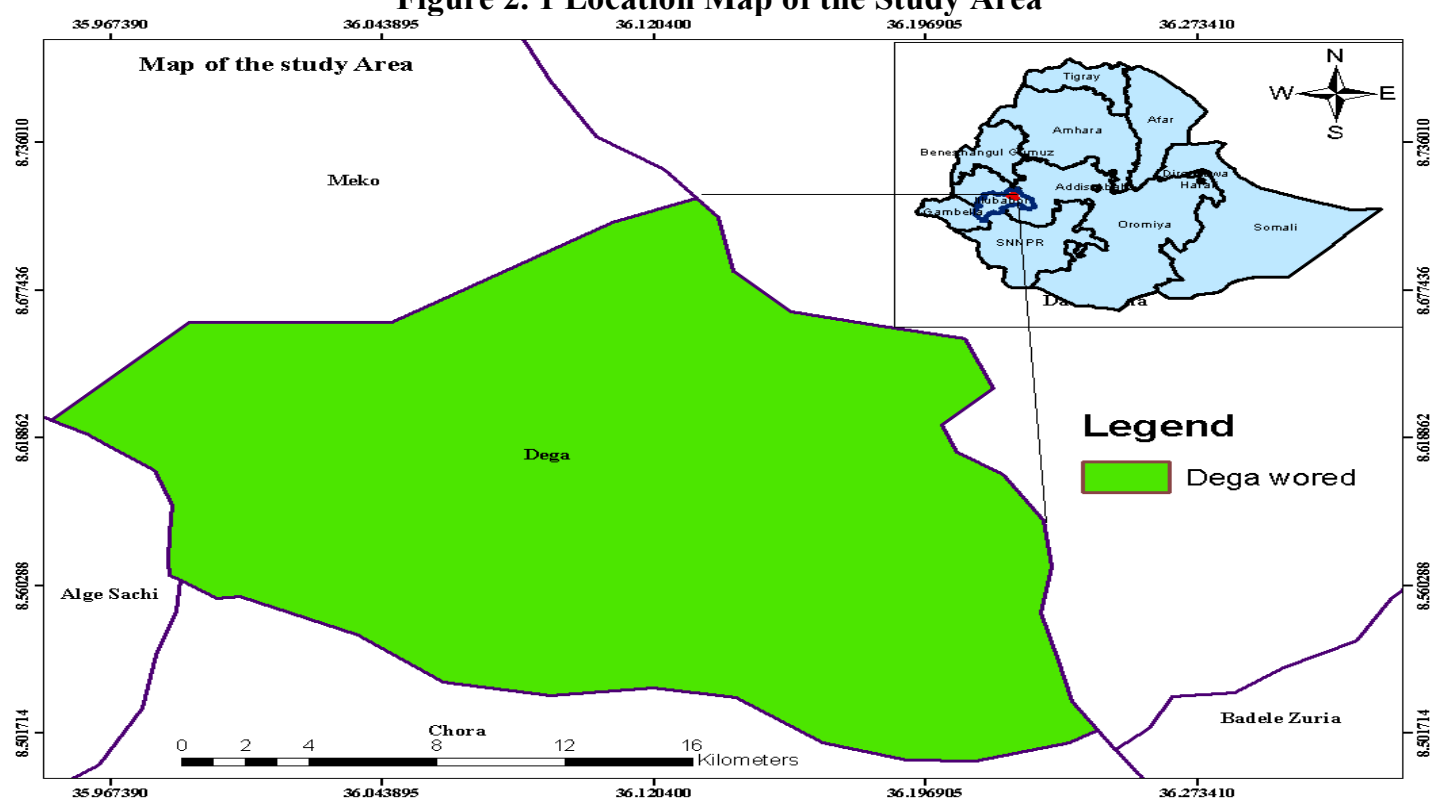

Source: depicted from a map of the country by using GIS, 2018

The above figure showed Oromia regional state, Buno Bedelle Zone, Degga woreda. This woreda was the study area that located in the western part of Ethiopia at the distance of $548 \mathrm{kms}$ from the capital city of Ethiopia, Addis Ababa and $68 \mathrm{kms}$ from Bedelle which is the capital city of Buno Bedelle zone. By the data received from the woreda cultural and tourism office, Degga woreda was established in 1872. It's bordered in the south by Chora and Bedelle woreda, in the west by Meko woreda, in the north by the Chawaka woreda and in the east by Dapho Hana woreda. The woreda has also 23 primary schools, 3 high schools, 1 preparatory school, 1 TVET College. Degga woreda has 16 rural kebeles and 1 town kebele with the total population of 54, 866 of whom 27,121 are men and 27,745 are women. The total area of land in this town is $460 \mathrm{~km}^{2}$ ( Degga woreda administration office 2019).

\section{Method of Data Analysis}

This study used descriptive statistics (mean and standard deviation) and inferential statistics (multiple linear correlations and multiple linear regressions). Also this study was supported by Statistical Package for Social Scientists (SPSS) 20 version to facilitate the data analysis and Structural equation model (AMOS) 22 version, to analyze the effect estimates between independent and dependent variables (Bollen and Stine's, 1992).

Modeling the Multiple Linear Regression Y= Bo + B1X1 +B2X2 + e1

Where: $\mathrm{X} 1=$ organizational leadership and $\mathrm{X} 2=$ training, $\mathrm{Y}=$ performance of teachers and el= error term.

\subsection{Mean Analysis}

Table 3.1 Overall Descriptive Summery of Independent and Dependent Variables

\begin{tabular}{llllll}
\hline Variables & $\mathrm{N}$ & Minimum & Maximum & Mean & Std. Deviation \\
\hline Training and development & 170 & 1 & 5 & 2.01 & 1.36 \\
Organizational leadership & 170 & 1 & 5 & 2.70 & .842 \\
Teacher's Performance & 170 & 1 & 5 & 2.48 & .812 \\
\hline
\end{tabular}

Source: Field data 2019 G.C

The above table explains that organizational leadership and training and development had an overall mean score of 2.70 and 2.01 respectively. This shows that an organizational leader was moderately rated by the respondents whereas training and development was show low mean.

\subsection{Multiple Correlation Analysis Results}

When there are two or more than two independent variables, the analysis concerning relationship is known as multiple correlations. Correlation is the coefficient that indicates the power of linear relationship between variables. This coefficient must be statistically significant in order to be able to say that there is a relationship between variables. The correlation coefficient takes a value between -1 and $+1,+1$ indicating a perfect positive correlation and -1 indicating perfect negative correlation between two variables (Kothari., 1990). 
Table 3. 2 Correlation between Independent Variables and Teachers Motivation

\begin{tabular}{|c|c|c|c|}
\hline Variables & 1 & 2 & 3 \\
\hline Teachers performance & 1 & & \\
\hline Training and development & -.096 & 1 & \\
\hline Organizational leadership & $.363 * *$ & $.190 *$ & 1 \\
\hline
\end{tabular}

**. Correlation is significant at the 0.01 level (2-tailed).

*. Correlation is significant at the 0.05 level (2-tailed).

Source: Field data 2019

The above table shows that there exist a correlation between independent variables and teachers' motivation. Correlation between Organizational leadership and teachers' motivation was the highest $(\mathrm{r}=0.363 ; \mathrm{p}<0.01)$ and the least correlation was between training and development and teachers' motivation $(\mathrm{r}=-0.096)$.

\subsection{Structural Equation Model Analysis}

\subsubsection{Fit Indices Test of Structural Equation Model}

Structural Equation Modeling (SEM) has become one of the techniques of choice for researchers across disciplines and increasingly is a must for researchers in the social sciences. However, the issue of how the model that best represents the data reflects underlying theory known as model fit. It is essential that researchers using the technique are comfortable with the area since assessing whether a specified model fits the data is one of the most important steps in structural equation modeling (Yuan, 2005).

Table 3. 3 Fit Indices Test of Structural Equation Model

\begin{tabular}{llllllll}
\hline Model & GFI & AGFI & RMR & NFI & CFI & PNFI & RMSEA \\
\hline Default Model & 1.000 & 0.999 & 0.001 & 1.000 & 1.000 & 0.048 & 0.52 \\
\hline Source: Field data 2019 & & & & & & &
\end{tabular}

As table above shows that the value of GFI and AGFI are 1and 0.999 which indicated that goodness of fit laid between range from 0 to 1 and indicated great model fit between 0.9-1 (Shevlin, 1998) and (Shevlin, 2007). Another, the value of RMR is 0.001 and that indicated between 0 to 1 , not only this RMR has a good model fit approach to zero (Bentler, 1999). Also the above table indicates that the value of NFI and CFI were equal 1 which belongs 0 to 1 and indicated good model fit above 0.9 (Bentler and Bonnet, 1980). However, the goodness of fit indices of PNFI indicated that good model fit by 0.048 , thus included between 0 and 0.5 (Mulaik, 1989). Finally, the value of RMSEA showed that good model fit to some extent by 0.52 , because it was found between good model fit 0.5-1 (Maccallum, 1996). Based on the above result of model indices components, the researcher concluded that the model was fit.

\subsubsection{Result of Regression Weights}

Regression analysis is adopted appropriate when the researcher has one dependent variable which is presumed to be a function of two or more variables (Kothari., 1990). Thus, the regression weight resulted from AMOS graphic was seat as below table.

Table 3.4. Result of Regression Weights

\begin{tabular}{lllllll}
\hline Variables & & & Estimate & S.E. & C.R. & P-value \\
\hline Performance of teachers & $<---$ & organizational leadership & .387 & .071 & 5.439 & .000 \\
Performance of teachers & $<---$ & Training and development & .170 & .044 & 3.876 & .000 \\
\hline
\end{tabular}

Source: Field data 2019G.C

The findings in the above table indicate that the regression weight for organizational leadership and training and development in the prediction of performance of teachers are significantly different from zero at the 0.001 level (two-tailed). This shows that training provides knowledge for teachers besides organizational leadership like responsibility and empowerment emerges knowledge necessary at different level of position.

3.3.3. Effect of Independent Variables on Dependent Variable Table 3. 5 Direct Effects of Independent Variables on Dependent Variable

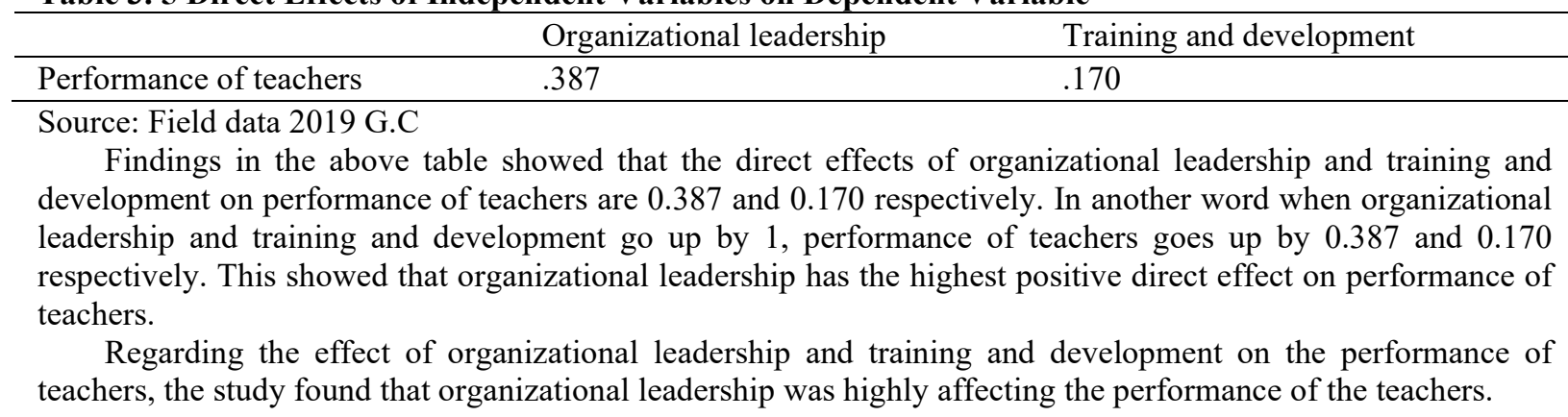




\section{Conclusions and Recommendations}

Also, from the result of the study it can be concluded that factors like organizational leadership and training and development have a high positive effect on the performance of teachers in Degga woreda public primary schools respectively. The outcome from motivated teachers will produce high level of productivity, lower the level of absenteeism and reduced turnover since teachers are enjoying their work. Therefore, understanding what factors motivates teachers in a given school becomes crucial matter in that it helps the principal concentrate more on those motivating factors and how to improve them. The multiplier effects of teacher's motivation on teacher's performance is that it effects directly on teacher's performance, safe costs arising from teacher absenteeism and turnover rate and also help boost organization bottom-line due to increased output.

The result of the study also indicated that effect of motivation factors on performance of teachers like organizational leadership; teachers' motivation, and training and development have an effect on performance of teachers. Therefore, regional education bureau, woreda education office and head of schools should have work together to prevent the effect of organizational leadership and training and development on the performance of teachers. By develop a national training and development policy and award programs based on performance, to enable teachers to upgrade their knowledge and skills and principals of the school should recognize teachers in their school even by words. Obviously, there was a problem but how much there is a problem teachers themselves should play a great role in maximizing productivity by asking their question side by side, because the issue is about sharpening the mind of new generation.

\section{REFERENCES}

Baldoni, J. (2005). Motivation Secret. Great Motivation Secret of Great Leaders (www page). URL http://govleaders.org/motivation secrets.htm.

Bentler, P.M. and Bonnet, D.C. (1980), "Significance Tests and Goodness of Fit in the Analysis of Covariance Structures," Psychological Bulletin, 88 (3), 588-606.

Bollen, K. A., and R. A. Stine. 1992. Bootstrapping goodness-of-fit measures in structural equation models. Sociological Methods and Research, 21: 205-229.

Clotfelter. (2006). Teacher-Student Matching and the Assessment of Teacher Effectiveness. Unpublished. Durham: Duke University.

Kinicki, A. (2007). Organizational Behavior, McGraw-Hill, New York, NY.

Kothari. (1990). Research Methodology, Methods and Techniques. Second Revised Edition. 1-303.

MacCallum, R.C., Browne, M.W., and Sugawara, H., M. (1996), "Power Analysis and Determination of Sample Size for Covariance Structure Modeling," Psychological Methods, 1 (2), 130-49.

Michael. (2002). Orgaanizational Leadership and Stratey in the Hospitality Industry. Journal of Services Research, Volume2, Number1, 1-29.

Rukhmani, K. (2010). Effect of Leadership Styles on Organizational Effectiveness. European Journal of Social Sciences, 15 (3) , 365-369.

Shevlin, M. (1998), "Effects of sample size, model specification and factor loadings on the GFI in confirmatory factor analysis," Personality and Individual Differences, 25, 85-90.

Shevlin, M. (2007), "A time and a place for incremental fit indices," Personality and Individual Differences, 42 (5), 869-74

Yamane T, L.(1967) .Statistics: An Introductory Analysis, $2^{\text {nd }}$ Edition. Harper and Row, New York.

Yuan, K.H. (2005), Fit Indices Versus Test Statistics, Multivariate Behavioral Research, 40 (1), 115-48. 